\title{
REFLEKSI BUDAYA BANJAR DAN DAYAK DALAM NOVEL JENDELA SERIBU SUNGAI KARYA MIRANDA SEFTIANA DAN AVESINA SOEBLI (KAJIAN ETNOLINGUISTIK)
}

(The Reflection of Banjar and Dayak Culture in the Novel Entitled Jendela Seribu Sungai By Miranda Seftiana and Avesina Soebli (Ethnolinguistics Study))

\author{
Indrawati \\ Balai Bahasa Provinsi Kalimantan Selatan \\ Jalan Ahmad Yani Km, 32 Loktabat Banjarbaru, Telepon (0511) 4772641 \\ indra_bhs73@yahoo.co.id
}

Diterima 7 Oktober 2020

Direvisi 14 Otober 2020

Disetujui 15 Oktober 2020

https://doi.org/10.26499/und.v16i2.2839

\begin{abstract}
Abstrak: Masyarakat Banjar dan Dayak masih memegang teguh budaya mereka masing-masing dan diikuti sampai sekarang. Bagaimana budaya itu direfleksikan oleh para tokoh dalam novel Jendela Seribu Sungai menjadi permasalahan dalam penelitian ini. Penelitian ini bertujuan mendeskripsikan budaya Banjar dan Dayak yang direfleksikan dalam novel Jendela Seribu Sungai karya Miranda Seftiana dan Avesina Soebli dikaji dari pendekatan etnolinguistik. Penelitian ini menggunakan metode deskriptif kualitatif, dengan tahapan membaca, menginventarisasi, mereduksi, menganalisis, dan terakhir memberi simpulan. Kesimpulan dari hasil penelitian ini bahwa refleksi budaya Banjar dan Dayak dalam novel Jendela Seribu Sungai dapat dilihat dari tradisi dan adat kebiasaan masyarakat Banjar dan Dayak yang masih dilaksanakan;, ungkapan dan peribahasa yang menjadi pedoman hidup masyarakat Banjar dan Dayak; ritual dan kepercayaan yang masih diyakini; permainan tradisional yang masih dimainkan oleh masyarakat Banjar dan Daya;, makanan tradisisonal yang menjadi ciri khas masyarakat Banjar dan Dayak; serta mantra atau doa yang masih dibaca dalam setiap prosesi upacara.
\end{abstract}

Kata kunci: etnolinguistik, refleksi, budaya

Abstract: Banjar and Dayak communities uphold their cultures and they still follow them until now. How that culture is reflected by the characters in the novel Jendela Seribu Sungai becomes an issue in this study. This research aims to describe Banjar and Dayak culture reflected in the novel Jendela Seribu Sungai by Miranda Seftiana and Avesina Soebli and it is reviewed from ethnolinguistics approach. The methods used in this study are qualitative descriptive methods by reading the novel Jendela Seribu Sungai, inventorying data, reducing data, analyzing data, and giving conclusion. From the results of this study it can be concluded that the reflections of Banjar and Dayak culture in the novel Jendela Seribu Sungai displays various traditions and customs of Banjar and Dayak communities and it still implemented; phrases and proverbs that become the guidelines of Banjar and Dayak people; rituals and beliefs that are still believed; traditional games that are often played by Banjar and Dayak people; food that becomes the characteristic of Banjar and Dayak people; and also spells or prayers that are still read in each ceremonial procession.

Keywords: ethnolinguistics, reflection, culture

\section{PENDAHULUAN}

Sebuah karya sastra yang diciptakan tentu tidak akan lepas dari latar belakang pengarangnya selain dari bahasa dan budaya. Kebudayaan seorang pengarang menjadi sebuah realita yang dapat 
mengilhami pembuatan karya sastra. Pengarang dapat menciptakan suatu karya sastra melalui pengamatan dari keadaan masyarakat di sekelilingnya..

Menurut Tumanggor, Ridlo, \& Nurochim (2010), budaya adalah perilaku masyarakat yang dipengaruhi oleh konsep, keyakinan, nilai, dan norma yang dianut oleh masyarakat itu sendiri (hlm. 141).

Seperti halnya novel Jendela Seribu Sungai karya Miranda \& Avesina (2018). Miranda Seftiana merupakan penulis kelahiran Hulu Sungai Selatan, Kalimantan Selatan. Dalam menciptakan novel yang berjudul Jendela Seribu Sungai Miranda Seftiana dan Avesina Soebli dipengaruhi oleh sistem budaya yang dianut. Tentu saja budaya kelompok masyarakat Hulu Sungai Selatan

Berdasarkan uraian di atas, banyak hal yang dapat diamati dari novel Jendela seribu Sungai, terutama latar belakang budaya dari para tokoh. Refleksi budaya Banjar dan budaya Dayak tercermin dalam alur cerita tokoh dalam novel. Novel ini mengeksplorasi sisi-sisi antropologis dari suatu masyarakat, yaitu masyarakat Banjar dan Dayak. Dalam novelnya pengarang mengangkat istilah-istilah lokal sebagai representasi budaya lokal. Selain istilah-istilah lokal yang digunakan, kelebihan dari novel Jendela Seribu Sungai, pengarang berhasil mempertemukan budaya sungai masyarakat Banjar dengan budaya pegunungan masyarakat Dayak di lembah Meratus. Keduanya memiliki sisi-sisi mitologis yang berbeda asal-usul, tetapi hidup dalam satu kawasan.

Penelitian ini bertujuan memerikan budaya Banjar dan Dayak melalui novel Jendela Seribu Sungai. Bagaimana pengarang merefleksikan budaya masyarakat Banjar dan masyarakat Dayak dalam sebuah cerita. Penelitian ini difokuskan pada analisis budaya masyarakat Banjar dan masyarakat Dayak yang tercermin dalam kehidupan tokoh-tokoh novel Jendela Seribu Sungai. Bagaimana budaya Banjar dan Dayak direfleksikan, itulah yang akan dibahas dalam penelitian ini.

Penelitian ini termasuk dalam ranah kajian etnolinguistik, yakni mengkaji budaya masyarakat Banjar dan masyarakat Dayak melalui tradisi dan adat kebiasaan, ritual upacara dan kepercayaan, ungkapan dan peribahasa, permainan tradisional, makanan yang merupakan wujud budaya.

Berbagai penelitian berkaitan dengan budaya suatu masyarakat atau kajian etnolinguistik pernah dilakukan, di antaranya, penelitian tentang "Representasi Budaya Jawa dan Barat dalam Novel Rahvayana karya Sujiwo Tejo" yang dilakukan Hermoyo, Hidayah, Yarno, \& Panji (2016) Penelitian ini mengkaji representasi budaya Jawa dan Barat serta akuturasi budaya Jawa dan Barat dalam novel Rahvayana karya Sujewo Tejo(hlm. 6280).

Sari (2019) juga pernah mengkaji tentang "Nilai Budaya dalam Leksikon Pendulangan Intan pada Masyarakat Banjar: Kajian Etnolinguistik". Penelitian ini mengkaji nilai budaya dalam leksikon pendulangan intan pada masayarakat Banjar dan mengklasifikasi berbagai istilah yang terdapat dalam leksikon pemdulangan intan pada masyarakat Banjar. Berbagai istilah yang berkaitan dengan budaya mendulang intan pada masyarakat Banjar dijelaskan dalam penelitian ini (hlm. 161).

Hanafi (2020) juga pernah melakukan penelitian mengenai “Refleksi Budaya Lampau Leksikon 
Kebendaan Peribahasa Banjar: Kajian Etnolinguistik" yang dimuat dalam jurnal ilmiah bahasa dan sastra Undas Volume 16 Nomor 1. Penelitian ini mengkaji leksikon kebendaan sebagai refleksi budaya masa lampau yang tertuang dalam peribahasa Banjar sebagai gambaran terhadap budaya (kebiasaan) etnik Banjar zaman dahulu atau masa yang sudah lampau (hlm. 93106).

Kajian mengenai budaya masyarakat Banjar dan Dayak dalam novel Jendela Seribu Sungai dapat menjadi bahan rujukan yang akan menambah kekayaan budaya bangsa.

\section{KERANGKA TEORI}

Etnolinguistik adalah bagian dari ilmu linguistik. Kajian etnolinguistik bukan saja mengkaji bahasa dari strukturnya, tetapi juga dari fungsi dan pemakaiannya dalam hubungannya dengan konteks sosial dan budaya.

Sugianto (2015) mengatakan etnolinguistik berasal dari gabungan kata etnologi dan linguistik atau penggabungan etnolog atau antropologi budaya dengan menggunakan pendekatan linguistik. Etnolinguistik itu sendiri bias sebagai kajian linguistik yang menjadi sumbangan bagi etnolog atau kajian etnologi yang memberikan sumbangan bagi linguistik (hlm. 51 -55).

Abdullah (dalam Yulianti, 2018), menyatakan bahwa etnolinguistik adalah kajian linguistik yang menaruh perhatian pada dimensi bahasa baik itu kosakata, frasa, klausa, wacana, serta unit-unit lingual lainnya dalam dimensi sosial dan budaya. Dimensi bahasa dalam kaitannya dengan budaya bisa dilihat dalam upacara ritual, peristiwa budaya, folklor, dan lainnya. Lebih luas lagi dikatakan bahwa tujuan etnolinguistik lebih ke arah memajukan dan mempertahankan praktik-praktik budaya dan struktur sosial masyarakat (hlm. 67).

Hal itu dipertegas Duranti (1997) yang menganggap etnolinguistik sebagai sebuah ilmu interdisipliner, di mana ilmu tersebut memakai dan menggunakan metode-metode yang terdapat dalam ilmu antropologi dan ilmu linguistic (hlm. 2-3).

Pendapat lain mengatakan bahwa etnolinguistik adalah studi keterkaitan antara bahasa dan kebudayaan. yaitu antara struktur dan penggunaan bahasa yang berkaitan dengan masyarakat, kebudayaan, dan perilaku penggunanya ((Endraswara, 2015, hlm. 59).

Bahasa dan kebudayaan berkaitan erat karena kedua aspek tersebut saling melengkapi, atau bisa salah satunya mendominasi terhadap aspek lainnya. Oleh karena itu, dapat dikatakan melalui bahasa dapat dipahami budaya pemakai bahasa itu ((Sibarani, 2004 hlm. 46).

Sementara itu, Foley (2001) berpendapat bahwa untuk mendapatkan pemahaman budaya, etnolinguistik merupakan cabang ilmu yang tepat dalam mengkaji bahasa dalam konteks sosial dan budaya yang lebih luas termasuk di dalamnya makna yang tersembunyi di balik penggunaan bahasa, pemakaian bentuk-bentuk bahasa yang berbeda, dan pemakaian register dan gaya (hlm. $3-5)$.

Berdasarkan pendapat di atas dapat disimpulkan bahwa untuk memahami budaya suatu masyarakat sebagai sebuah fenomena budaya dapat dikaji dengan sudut pandang etnolinguistik. 


\section{METODE PENELITIAN}

Penelitian ini menggunakan metode desktiptif kualitatif. Peneliti mendeskripsikan budaya masyarakat Banjar dan Dayak yang direfleksikan dalam novel Jendela Seribu Sungai. Sumber data penelitian, yakni novel Jendela Seribu Sungai karya Miranda Seftiana dan Avesina Soebli dengan jumlah 303 halaman dan panjang $13 \mathrm{~cm}$. Novel tersebut diterbitan oleh Penerbit Grasindo pada tahun 2018 di Jakarta. Sampul novel berwarna dasar biru terdapat gambar jendela. Sementara, yang menjadi objek penelitian adalah refleksi budaya Banjar dan Dayak dalam novel tersebut. Langkah pengumpulan data yang dilakukan adalah membaca novel, menginventarisasi data, mereduksi data, menganalisis data, dan memberi simpulan. Selanjutnya, teknik analisis data yang digunakan adalah teknik analisis data model Miles dan Huberman (dalam Sugiyono, 2012) yang terdiri atas reduksi data, penyajian data, dan penarikan kesimpulan (hlm. 337).

Peneliti mengumpulkan data berupa kutipan kalimat atau paragraf yang diambil dalam novel Jendela Seribu Sungai karya Miranda \& Avesina (2018). Novel ini merefleksikan budaya Banjar dan budaya Dayak yang berhubungan dengan rumusan masalah. Hal itu sependapat dengan Ratna (2013), yang menyatakan bahwa penelitian kualitatif adalah penelitian yang analisisnya didasarkan pada deskripsi permasalahan secara keseluruhan sehingga pada akhirnya menghasilkan suatu simpulan (hlm. 351).

Teknik pengumpulan data menggunakan studi kepustakaan melalui teknik catat, yaitu dengan mencatat hal atau temuan data yang akan dianalisis. tahapan-tahapan yang digunakan adalah
(1) membaca novel Jendela Seribu Sungai, (2) menandai data yang termasuk dalam budaya Banjar dan budaya Dayak yang berupa kalimat, paragraf, dan tuturan tokoh dalam novel yang sesuai dengan rumusan masalah, dan (3) mencatat data tersebut untuk dianalisis. Menurut Faruk (2012), data diambil yang sesuai dengan objek penelitian. Setelah data terkumpul tahap selanjutnya adalah pengolahan data. Pengolahan data dilakukan dengan menelaah data dan menganalisis data (hlm. 56).

Menurut Ratna (2013), untuk menganalisis sebuah karya sastra perlu pemahaman sebuah teks. Akan tetapi, lebih tepat jika menggunakan penafsiran karena objek apapun bentuknya akan dianggap sebagai sebuah bahasa atau wacana (hlm. 354).

\section{HASIL DAN PEMBAHASAN 4,1 Sinopsis}

Cerita novel ini diawali persahabatan tiga orang anak yang bernama Arian, Bunga, dan Kejora. Arian adalah anak seorang seniman kuriding. Arian tidak pernah menyangka pertemuannya dengan Bunga yang seorang gadis penderita cerebal palsy, dan Kejora seorang gadis dari Pegunungan Meratus, membawanya menghadapi petualangan yang tidak pernah diduga sebelumnya. Arian yang selalu mendapat nasihat dari sang abah (ayah) melalui kuriding merasa bertangggung jawab menjaga dua gadis tersebut. Nasihat kuriding dari abah (ayah) menjadi pedoman Arian dalam menjalani hidup dan bergaul dengan siapapun termasuk teman-temannya. Arian, Bunga, dan Kejora adalah anak-anak berasal dari tempat dan budaya yang berbeda. Akan tetapi, mereka memiliki semangat yang sama dalam mewujudkan mimpinya masing-masing. Arian hanya bermimpi bisa mengiringi grup musik Radja dengan kuriding. Bunga bermimpi ingin 
menjadi penari. Sementara itu, Kejora hanya memiliki keinginan kuat untuk bersekolah. Dalam petualangannya ketiga anak tersebut sering terlibat konflik. Arian dan Bunga mewakili masyarakat yang tinggal di sepanjang aliran sungai, sedangkan Kejora mewakili masyarakat di lereng gunung. Perbedaan budaya yang dimiliki ketiganya terlihat melalui dialog, konflik batin, hingga tindakan dari tokoh.

\subsection{Refleksi Budaya Banjar dan Dayak dalam Novel Jendela Seribu Sungai}

Salah satu suku terbesar yang ada di Indonesia adalah suku Banjar dan Dayak. suku Banjar mendiami wilayah Kalimantan Selatan, sedangkan suku Dayak hampir mendiami di seluruh Kalimantan. Suku Banjar dan Dayak memiliki karakteristik budaya. Hal itu dapat dilihat dari kehidupan sehari-hari masyarakat Banjar dan Dayak, khususnya dalam bentuk kesenian, tarian, musik, pakaian, permainan, dan upacara ttadisional. Berikut ini beberapa budaya Banjar dan Dayak yang direfleksikan dalam novel Jendela Seribu Sungai.

\subsubsection{Refleksi Tradisi dan Adat Kebiasaan \\ Masyarakat Banjar memiliki} tradisi dan adat kebiasaan yang masih dijalankan hingga sekarang. Menurut Sztompka (2008), tradisi hanyalah warisan masa lalu yang masih tersisa (hlm. 69). Sementara itu, Wajidi (2011) mengatakan bahwa tradisi lahir dari kekaguman yang kemudian berubah menjadi perilaku dalam bentuk upacara (hlm. 8). Salah satu tradisi masyarakat Banjar yang direfleksikan dalam novel Jendela Seribu Sungai adalah upacara adat tian mandaring. Upacara adat dilakukan sebagai ungkapan rasa syukur akan lahirnya seorang bayi. Berikut ini kutipan yang menggambarkan tradisi tian mandaring.

“Orang-orang Antasan Timur dan Barat saling bersulang harap, sebab mereka tahu perlu sebelas tahun bagi si pengusaha batubara untuk menggelar acara Tian Mandaring. Bukan perihal dana yang ia tidak mampu, melainkan keturunan yang tak kunjung bermukim di rahim sang istri (Miranda \& Avesina, 2018, hlm. 12).

Pada kutipan di atas dijelaskan bahwa akan diadakan acara tian mandaring untuk istri pengusaha batubara yang sudah belasan tahun menanti kehamilan. Dengan diadakannya upacara tian mandaring orang-orang Antasan Timur dan Barat berharap ibu dan bayi yang dikandungnya selamat.

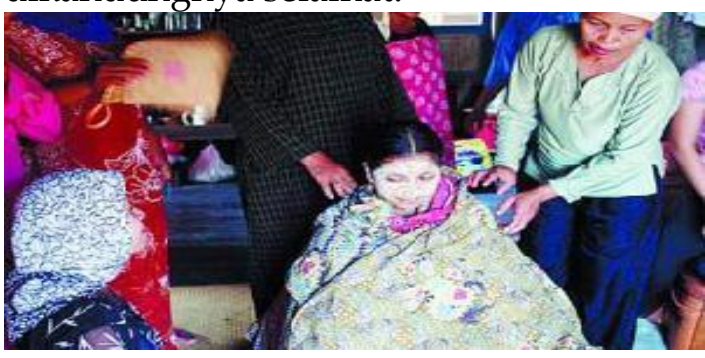

Gambar 1 Upacara Tian Mandaring Sumber:("Upacara adat Kalimantan Selatan," 2013)

Tradisi upacara tian mandaring dilakukan sewaktu kandungan seorang ibu berumur tujuh bulan. Masyarakat Banjar percaya, ketika usia kandungan tujuh bulan banyak diikuti roh halus. Bayi akan sulit lahir kalau tidak ditebus. Tradisi upacara Mandi Tian Mandaring atau disebut juga dengan istilah bapagar mayang Hal itu karena pada upacara Mandi Tian Mandaring menggunakan pagar mayang. Mayang-mayang pinang digantungkan di sekililing tempat pemandian. Biasanya calon ibu yang 
akan dimandikan didandani dengan pakaian sebagus mungkin.

Pelaksanaan upara ini dilakukan dengan menyiram kepala wanita tian mandaring oleh lima atau tujuh orang wanita dengan air bunga yang telah disediakan. Salah seorng wanita yang dianggp paling berpengaruh diserahi tugas memegang upung mayang yang masih terkatup di atas kepala. Upung mayang dipukul sekeras-kerasnya. Menurut kepercayaan masyarakat Banjar, apabila dalam satu kali pukul sudah pecah wanita tian mandaring tidak akan mengalami gangguan sampai melahirkan.

Setelah selesai upacara calon ibu tersebut dibawa ke dalam rumah untuk disisir, dirias, dan diberi pakaian yang bagus. Upacara ini akan diakhiri dengan bersalam-salaman sambil membaca doa untuk si calon ibu tersebut.

\subsubsection{Ungkapan atau Peribahasa}

Menurut Brunvand (dalam (Danandjaja, 2002) peribahasa sesungguhnya adalah ungkapan tradisonal yang kalimatnya lengkap, bentuknya kurang mengalami perubahan, mengandung kebenaran dan kebijaksanaan (hlm. 29). Sementara itu, Ganie (dalam Hanafi, 2020), mengatakan bahwa ungkapan tradisonal bahasa Banjar merupakan bahasa masyarakat Banjar yang digunakan untuk menggambarkan pola pikir, pengalaman dan kebudayaannya (hlm. 96-97).

Ungkapan atau peribahasa dalam

novel Jendela Seribu Sungai yang merefleksikan budaya masyarakat Banjar dan Dayak dapat dilihat dalam kutipankutipan berikut.

\section{Ungkapan Bauntung Batuah}

Ungkapan bauntung batuah

biasanya diucapkan oleh orang tua kepada anaknya yang akan merantau. Ungkapan tersebut merupakan konsepsi manusia yang diharapkan oleh masyarakat Banjar kepada keturunannya. Ungkapan bauntung batuah dalam novel Jendela Seribu Sungai dapat dilihat dari kutipan berikut.

"Bauntung, batuah, Arian!" teriak uma dari jendela samping. Ia mengancungacungkan seikat pandan, seperti atlet lempar lembig. "Pantas dipanggil tidak menyahut, Ian Kasela yang ditiru rupanya.". (Miranda \& Avesina, 2018, hlm. 85)

Kata bauntung, batuah pada kutipan di atas merupakan doa yang diteriakkan ibu Arian untuk anaknya Arian. Bauntung maknanya adalah bermanfaat atau berguna, tidak hanya sekadar untung. Kata untung sendiri dalam bahasa Banjar berarti bernasib baik. Kehidupan seorang anak akan bermanfaat dan berguna bagi dirinya, orang lain, masyarakat, dan lungkungan dengan berbekal iman dan ilmu agama sehingga diharapkan si anak tersebut akan bernasib baik. Bukan karena keberuntungan semata, tetapi ada koridor keimanan yang menjadi dasar dari proses keilmuan untuk pemanfaatan dirinya. Sementara itu, kata batuah bermakna menjadi manusia yang memiliki harkat dan martabat, bahkan bisa menjadi karamah. Paling tidak si anak memiliki martabat yang mulia baik dunia maupun akhirat. Kata batuah lebih dimaknai bagaimana kebermanfaatan manusia baik di dunia maupun akhirat yang dasarnya iman yang kuat dan ilmu yang mumpuni (Sarbaini, 2016). 


\section{Peribahasa Kada Titik Banyu Diganggam \\ Kada titik banyu diganggam} mengandung arti tidak menetes air walau digenggam. Masyarakat Banjar mengiaskan peribahasa tersebut sebagai gambaran seseorang yang sangat kikir dan tidak mau memberikan hartanya. Kata kada dalam bahasa Banjar berarti tidak, banyu artinya air. Berdasarkan sifatnya air merupakan benda cair yang pasti akan mengalir walaupun di selasela lubang yang kecil. Akan tetapi, peribahasa tersebut mengiaskan orang yang terlalu pelit sehingga walaupun setitik pun orang tersebut tidak akan memberikan hartanya. Berikut kutipan yang menggambarkan peribahasa kada titik banyu digenggam.

"Amat kedua adalah jelma nyata peribahasa kada titik banyu diganggam; tidak menetes walau digenggam. Sebuah gambaran masyarakat Banjarmasin bagi orang demikian pelit atas hartanya. Oleh sebab itu, Amat digelari Amat Pangasit yang berarti pelit....(Miranda \& Avesina, 2018, hlm. 79)

Ungkapan dalam kutipan di atas jelas ditujukan kepada Amat, sebagai gambaran seseorang yang sangat kikir. Amat digambarkan sebagai seseorang yang memandang bahwa harta kekayaan yang dimilikinya merupakan hasil jerih payahnya dan tidak boleh ada orang lain yang menikmatinya. Begitu pelitnya, sampai-sampai berat sekali baginya untuk menyumbangkan sebagian hasil kekayaannnya itu.

Padahal, perlu kita sadari dalam kehidupan bermasyarakat kita dituntut untuk bersifat tolong-menolong. Mengingat masih banyak orang lain yang memerlukan bantuan dan sentuhan tangan orang-orang yang memiliki harta lebih. Nilai sosial yang dapat kita petik dalam kehidupan sehari-hari, kita perlu tolong-menolong, menafkahkan rezeki yang kita dapat dan tentunya tidak hanya berpangku tangan untuk kepentingan bersama.

\section{Ungkapan Sandu Bakut}

Bakut adalah sa;ah satu ikan yang paling sering dimakan. Bagian atas kepalanya pipih mirip ikan haruan (gabus), tetapi sebenarnya bukan. Tubuhnya malah seperti ikan sapu-sapu dengan kulit seperti warna sungai.

"Sandu bakut," ceplosku tak sengaja. Wajah bunga langsung masam.

...."Pemalu, Bunga," ralatku tidak setuju. "makanya ada ungkapan sandu bakut, kalau diperhatikan dia diam, sekali lengah langsung melompat jauh. Kau juga begitu, kadang tidak disangka ulahnya." (Miranda \& Avesina, 2018, hlm. 259)

Dalam kutipan di atas ungkapan sandu bakut dikiaskan seseorang yang kelihatannya pendiam, tetapi sebenarnya tidak. Orang ini tidak ingin orang lain mengetahui jati dirinya atau perilaku tidak baik yang dimilikinya. Dengan sifatnya itu, dia berusaha mengelabui semua orang yang pada dasarnya mempunyai perilaku tidak baik (Hasanah, 2013).

\subsubsection{Ritual dan Kepercayaan}

Dalam masarakat Banjar dan Dayak ada beberapa ritual dan kepercayaan yang mereka yakini. Berikut beberapa ritual dan kepercayaan yang terdapat dalam novel Jendela Seribu Sungai.

\section{Kapidaraan}

Kapidaraan merupakan mitos kepercayaan masyarakat Banjar terhadap 
gangguan makhlus halus. Umumnya yang sering kapidaraan adalah bayi atau anak kecil, tetapi tidak menutup kemungkinan kapidaraan menimpa orang dewasa yang jiwanya lamah atau sedang kosong yang biasanya disebut lamah bulu. Jika, bayi atau anak kecil yang kapidaraan akan menjadi rewel, badan panas, dan tidak bisa tidur. Menurut kepercayaan masyarakat Banjar kapidaraan disebabkan oleh makhluk halus yang menegur atau menyapa. Akibatnya, seseorang yang ditegur itu tidak kuat menanggungnya hingga membuatnya sakit. Sakit oarng yang kapidaraan biasanya badan panas, tetapi telinga, telapak tangan dan kaki dingin. Kepercayaan masyarakat Banjar mengenai kapidaraan yang direfleksikan dalam novel Jendela Seribu Sungai dapat dilihat dalam kutipan berikut.

“....aku mulai berpikir Bunga bukan hanya kapidaraan penunggu Sungai Keramat, tapi mungkin juga diikuti makhluk halus penunggu pohon beringin di samping gedung Balairung Sari". (Miranda \& Avesina, 2018, hlm. 123)

“...Seandainya memang benar Bunga kapidaraan atau ditegur penunggu Sungai Keramat maupun pohon beringin samping gedung Balairung Sari, maka aku harus meminta ampun pada papa mamanya. Karena bagaimanapun juga, aku telah membuat Bunga melanggar petuah kuriding kedua". (hlm. 114-115)

"Tubuhku langsung lunglai. Bunga tidak kapidaraan. Bunga masih waras, tidak memiliki tanda-tanda gila. Lalu dia kenapa?" (Miranda \& Avesina, 2018, hlm. 117)

Kapidaraan sendiri berasal dari kata pidara, artinya arwah atau roh orang yang sudah meninggal dunia, sedangkan $k a$ artinya penyebab. Jadi, kapidaraan bermakna arwah atau roh yang menjadi penyebab menyapa seseorang.

Secara medis, kapidaraan sangat identik dengan panas tinggi atau demam. Akan tetapi, orang yang kapidaraan walaupun diberikan obat penurun panas dijamin tidak akan sembuh karena kapidaraan bukanlah suatu penyakit. Kapidaraan bisa diobati dengan menggunakan parutan janar (kunyit) dan kapur sirih sambil dibacakan doa, kemudian dicontengkan dahi, leher, dada, perut, punggung, lutu, dan betis. Tanda silang yang ditorehkan melambangkan tolak bala yang sangat dipercaya sebagai simbol yang ditakuti roh-roh serta arwah yang ingin mendekat.

Kapidaraan bisa disembuhkan hanya dengan sepotong kunyit melalui ritual dan bacaan. Teknik pengobatan yang dilakukan tidak masuk akal. Bagi orang yang tidak mempercayai, hal tersebut merasa hanya sebuah kepercayaan masyarakat Banjar. Akan tetapi, bagi yang percaya ini merupakan suatu pengobatan yang terbukti ampuh.

\section{Bapalas}

Bapalas adalah ritual penyucian oleh etnis Dayak Meratus. Ritual ini bertujuan agar siapa pun yang berada di tempat itu terhindar dari roh jahat dan malapetaka. Istilah orang umum adalah mohon permisi. Ritual ini lahir karena masyarakat Dayak mempercayai keberadaan roh. Berikut kutipan ritual bapalas dalam novel Jendela Seribu Sungai (Miranda \& Avesina, 2018, hlm. 298).

“Balian Dungtambit mengangguk, ia berjalan mengekori Pangulu Isman mengitari untuk melaksanakan 
bapalas sebagai prosesi penyucian areal upacara sebelum aruh dimulai. Darah ayam dipercikkan ke lantai, enam tiang utama balai, dan seluruh permukaan meja panggung lalaya di tempat sesaji diletakkan. Lalu, perlahan darah ayam yang telah berpadu air ruas bambu menetes ke tanah dari celah lantai". (Miranda \& Avesina, 2018, hlm. 4)

Ritual ini biasanya dipimpin oleh seorang balian yang bagi masyarakat Dayak sebagai orang pintar dan sakti. Seorang balian diyakini dapat menghubungkan dunia alam gaib dengan dunia manusia.

Dari kutipan di atas dapat digambarkan bahwa dalam ritual bapalas terdapat sejumlah sesaji yang harus disiapkan dan mantra yang dibaca oleh balian. Ketika membaca mantra pun seorang balian pantang menatap lantai. Masyarakat Dayak mempercayai bahwa di bawah sana para hantu sedang menggoda manusia agar melainkan wajah dari Nini Bahatara, yang dianggap Tuhan orang-orang kaharingan.

\section{Tatamba}

Tatamba adalah upacara ritual peyembuhan atau pengobatan. Tradisi ini masih sangat kuat pengaruhnya dalam masyarakat Banjar dan Dayak. Hal itu terlihat dalam kutipan berikut.

"Menjelang aruh ganal, aku akan ikut Bapang memetik pucuk enau untuk hiasan panggung lalaya. Bapang mengenalkanku dengan rimpang, akar, atau dedaunan yang gunakan untuk tatamba (Miranda \& Avesina, 2018, hlm. 92).

Kutipan di atas dijelaskan bahwa di dalam ritual tatamba atau upacara ritual penyembuhan atau pengobatan dalam masyarakat Dayak memerlukan syarat- syarat yang harus disiapkan, seperti rimpang, akar, dan dedaunan.

“....Malam segera bertandang dan upacara tatamba babalian akan segera dimulai. Umbun -kerukunan- balai Haratai makin marapat, kami duduk melingkari bagian tengah balai yang dipisahkan undakan. Areal ini sakral, dibangun dari bambu, tempat upacara dilagsungkan". (Miranda \& Avesina, 2018, hlm. 223)

Dalam kutipan tersebut tatamba dilakukan untuk menyembuhkan ayah Damang Isman atau kakek Kejora. Hal itu dilakukan atas nasihat orang sekampung Haratai. Dalam upacara tersebut diperlukan selembar daun halinjuang darah. Daun tersebut memangn susah dicari, tetapi ternyata seekor bidawang mengantarkan daun halinjuang ke rumah Damang Isman. Daun tersebut diletakkan di dada kakek Kejora yang sering sakit dan sesak. Dia atas daun tersebut diletakkan pula seruas kencur. Kencur merupakan bagian dari rarampahan daalm setiap prosesi penyembuhan. Daun halinjuang melambangkan darah, sedangkan umbi kencur melambangkan air. Darah dan air merupakan dua unsur penunjang tubuh manusia (Miranda \& Avesina, 2018, hlm. 224).

Dalam masyarakat Dayak Meratus upacara tatamba biasanya diselingi tarian tandik putir balian. Tarian tersebut merupakan tarian khusus untuk upacara tatamba dengan diiringi tabuhan gendang. Seorang balian menarikannya sambil membaca mantra memutari tubuh orang yang sakit searah jarum jam.

\section{Kamurawaan}

Masyarakat Banjar adalah masyarakat yang sebagian masih percaya dengan hal-hal yang gaib. Gaib di sini 
sebagai 'sesuatu yang tersembunyi, tidak kelihatan, atau tidak diketahui sebabsebabnya'. Dalam masyarakat Banjar gangguan orang gaib terhadap manusia dikenal dengan istilah kamurawaan.

Kamurawaan menurut masyarakat Banjar sakit yang disebabkan oleh orang gaib (Miranda \& Avesina, 2018, hlm. 300). Kepercayaan orang Banjar mengenai kamurawaan direfleksikan dalam novel Jendela Seribu Sungai, seperti kita lihat pada kutiban di bawah ini

"Beruntung Uma belum datang. Jika ia ada sekarang, aku yakin sudah pasti dimandikan dengan air kembang dari sumur makam Sultan Suriansyah beserta anak keturunannya. Mungkin Uma akan mengira aku kamurawaan anak orang China yang pernah mati tenggelam di sungai lalu jasadnya ditemukan dalam sumur peninggalan kasultanan Banjar". (Miranda \& Avesina, 2018, hlm. 84)

Dalam kutipan di atas dapat dijelaskan bahwa karena tingkah laku Arian yang tidak seperti biasanya sehingga takut Umanya mengira Arian diganggu makhluk gaib yang berasal dari arwah orang China yang mati tenggelam di sungai.

\subsubsection{Permainan Tradisional}

Permainan tradisional menurut Mulyani (2016) adalah suatu permainan warisan dari nenek motyang yang wajib dan perlu dilestarikan karena mengandung nilai-nilai kearifan lokal (hlm. 47-48). Sejalan dengan pernyataan tersebut, Marzoan dan Hamidi (2017), menyimpulkan bahwa permainan tradisional merupakan kegiatan yang dilakukan dengan sukarela dan menimbulkan kesenangan bagi pelakunya, diatur oleh peraturan permainan yang dijalankan berdasar tradisi turun-temurun (hlm. 46).

Menurut Danandjaja (2002) permainan tradisional adalah salah satu bentuk permainan anak-anak yang beredar secara lisan maupun secara anggota kolektif, berbentuk tradisional dan diwariskan secara turun-temurun serta banyak memiliki variasi dalam satu jenis permainan (hlm. 29). Sementara itu, Kurniati (2016) mengatakan permainan tradisional merupakan suatu aktivitas permainan yang tumbuh dan berkembang di daerah tertentu, yang sarat dengan nilai-nilai budaya dan tata nilai kehidupan masyarakat dan diajarkan turun-temurun dari satu generasi ke generasi berikutnya (hlm. 2).

\section{Batarik Upih}

Batarik upih merupakan salah satu permainan tradisional yang dimainkan oleh anak-anak di beberapa negara, termasuk di Indonesia. Upih adalah nama dahan dari pelepah pinang yang sudah tua dan akan jatuh ke tanah pada masanya. Pada zaman dahulu upih yang sudah tua banyak sekali manfaatnya. Salah satunya sebagai alat permainan tradisional Wikipedia.org)

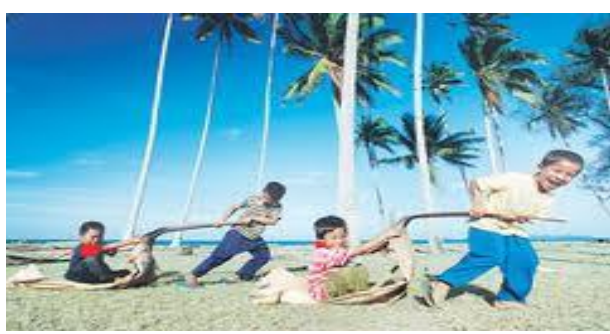

Gambar 1 Tarik Upih

Sumber:(Wikipedia, 2020)

"mereka mau adu batarik upih," ujar Ganang. Kalau mereka minta ambilkan pelepah pisang lagi, aku tidak mau!" 
Dalam permainan batarik upih, aku memang biasa ditugasi memanjat pohon pinang yang tumbuh di depan puskesmas." (Miranda \& Avesina, 2018, hlm. 25)

Permainan batarik upih biasanya dimainkan oleh dua orang atau lebih. Satu orang menjadi tukang tarik dan satu, dua, atau tiga orang lagi duduk di atas upih. Pemenang dari permainan ini adalah siapa yang sampai terlebih dahulu di garis finish.

\section{Bapidak}

Bapidak merupakan permainan tradisional yang sering dimainkan oleh anak-anak Banjar di daerah yang biasanya banyak terdapat perkebunan karet. Bapidak umumnya dimainkan oleh anak laki-laki. Permainan ini sangat menarik karena dituntut memiliki insting dalam memilih biji karet yang kuat.

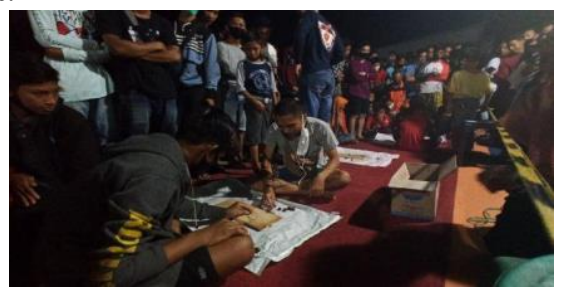

Gambar 2 Bapidak Sumber: (Banua, 2020)

“.... Di musim kemarau akhir seperti sekarang, bulan Agustus setengah bulatan, dedaunan dan ranting pohon karet berguguran. Buahnya telah dipungut anak-anak untuk permainan bapidak -adu kuat antara dua biji karet". (hlm. 202)

Dari kutipan di atas dapat digambarkan bahwa permainan ini memanfaatkan biji karet sebagai media permainan. Cara memainkannya dua buah biji karet ditumpuk ke atas dan ditahan dengan jari-jari tangan kiri. Sementara, tangan yang berdekatan dengan jari kelingking dipukulkan dengan keras ke tumpukan kedua biji karet. Hal itu dilakukan sampai salah satu biji karet tersebut pecah. Biji karet yang pecah dianggap kalah, sedangkan yang tidak pecah dianggap sebagai pemenang.

Dalam setiap permainan bisa dilakukan secara berkelompok atau satu lawan satu. Setiap orang akan memilih biji karet yang tidak mudah pecah. Ada ciri-ciri dalam memilih biji karet yang akan diadu. Biasanya biji karet yang kuat ditentukan dari kulit dan bentuk. Biji karet yang berkulit tebal dan bentuknya agak lonjong lebih kuat dibanding yang bentuknya bundar. Sementara, ketebalan biji karet tidak bias dilihat. Jadi, kita harus mengandalkan insting saja.

\subsubsection{Makanan Tradsional}

Salah satu budaya banjar dan Dayak yang direfleksikan dalam novel Jendela Seribu Sungai adalah makanan tradisional. Mengapa disebut makanan tradisonal karena makanan tersebut biasa dikonsumsi oleh masyarakat tertentu. Dalam penelitian ini tentu saja makanan yang dikonsumsi masyarakat Banjar dan Dayak. Makanan tradisional yang direfleksikan dalam novel Jendela Seribu Sungai dapat kita perhatikan sebagai berikut.

\section{Cacapan}

Masyarakat Banjar memiliki banyak ragam makanan khas tradisional, salah satunya cacapan. Makanan ini identik dengan masyarakat Banjar.

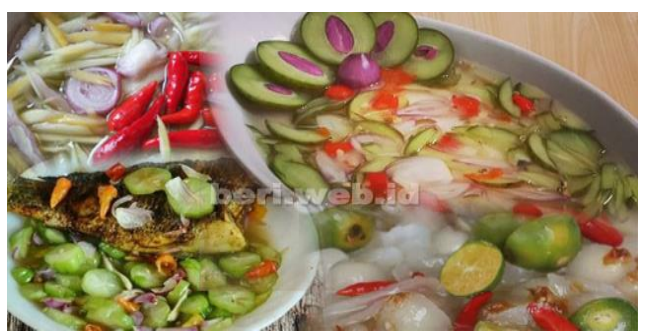

Gambar 3 Cacapan 
Dalam bahasa Banjar cacapan artinya cocolan. Masyarakat Banjar biasa mengkonsumsi cocolan sebagai makanan pendamping ikan atau hanya sekadar telur rebus. Selain mangga, belimbing tunjuk, kalangkala, ramania, atau asam jawa bias dijadikan bahan untuk cacapan. Makanan khas masyarakat Banjar dan Dayak ini juga digambarkan dalam kutipan berikut.

\begin{abstract}
"Bukan. Ini tatamba lapar," terangku sambil mencampurkan irisan cabe rawit, garam, terasi dan air lali mengaduk semuanya. Kukeluarkan tiga ekor ikan sepat siam yang dijemur sehari oleh Ganang kemudian merendamnya dalam cacapan. "Ini namanya buah rambai padi,"aku menyerahkan piring cacapan pada Kejora (Miranda \& Avesina, 2018, hlm. 164).
\end{abstract}

Proses pembuatan makanan ini, cukup mencampurkan semua bahan dengan air matang panas kemudian diaduk rata. bahan yang wajib adala untuk membuat makanan ini adalah garam, penyedap rasa, irisan bawang merah, irisan cabe rawit, dan terasi jika diperlukan.

Cara makannya sangat mudah. Cukup dengan ikan yang sudah digoreng dimasukkan dalam air cacapan atau cacapan disiramkan pada nasi.

\section{Garih Batanak}

Garih batanak adalah makanan yang menggunakan ikan garih sejenis haruan sebagai bahan utamanya. Kata garih sendiri adalah ikan yang diasinkan, tetapi biasanya tidak terlalu kering (masih ada ba'al "basah" sedikit). Haruan adalah ikan gabus, sedangkan batanak secara leksikal artinya adalah memasak.

Makna gramatikal dari istilah kuliner garih haruan batanak adalah masakan berbahan dasar ikan haruan yang diasinkan berikut makanan pelengkapnya atau dalam bahasa Jawa ubarampe-nya.

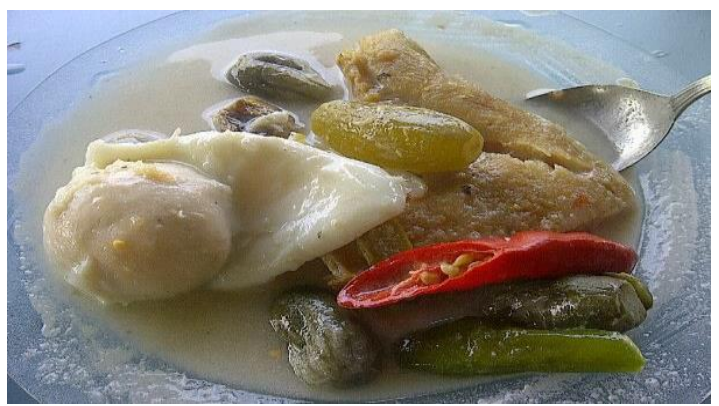

Gambar 4 Garih Batanak

Sumber:https://rizkikulinerbanua.blogspot.com/2 015/06/garih-batanak-kalimantanselatan.html

"Lebih mirip jambu mawar," gumam Kejora. "Kalau di kampungku rambai itu mirip langsat, Arian, kulitnya biasa dipakai untuk bumbu masak garih batanak. Sajian istimewa saat aruh ganal." (Miranda \& Avesina, 2018, hlm. 164)

Dapat disimpulkan bahwa makna gramatikal dari istilah garih haruan batanak adalah masakan berbahan dasar ikan haruan atau ikan gabus yang sudah diasinkan untuk bahan mengolah kuliner garih batanak.

\section{Pundut}

Pundut adalah salah satu makanan tradisional khas Banjar. Sesuai namanya pundut dalam bahasa Banjar berarti bungkus. Makanan ini terbuat dari beras yang dikukus. Refleksi makanan tradisional masyarakat Banjar dapat dilihat pada kutipan di bawah ini.

“...Uma menghampiri dengan nampan berisi empat bungkus pundut. Ia kemudian menarik lidi yang disematkan pengunci daun pisang..." (Miranda \& Avesina, 2018, hlm. 188) 


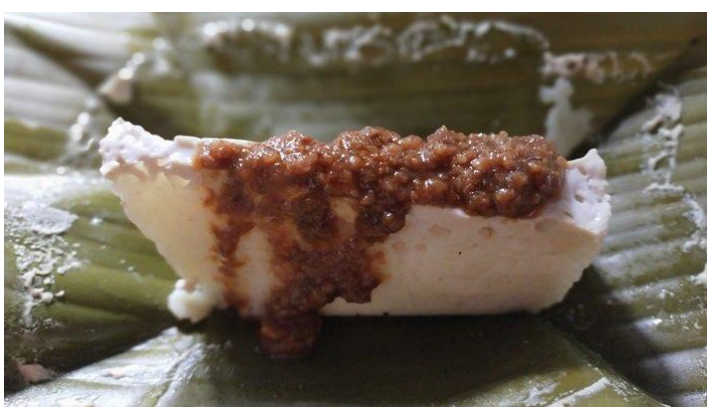

Gambar 5 Pundut Nasi

Sumber:

https://banjarmasin.tribunnews.com/2019/04/02/ kalselpedia-pundut-nasi-makanan-tradisionalkhas-banjar-kalimantan-selatan

Dari kutipan di atas dapat digambarkan bahwa makanan tradisional masyarakat Banjar pundut merupakan makanan yang dibungkus oleh daun pisang. Aroma daun pisang berpadu beras yang ditanak dengan santan hingga menyerupai lontong. Setelah masak santan biasanya akan mengental di puncak pundut dengan bentuk serupa gunung es. Pundut biasanya dimakan dengan siraman sambel habang di atasnya (Seftiana dan Soebli, 2018, hlm. 189)

\subsubsection{Mantra}

Mantra adalah kumpulan katakata yang dipercaya mempunyai kekuatan mistis atau gaib. Mantra pada masyarakat Melayu bukan dianggap sebuah karya sastra, tetapi lebih berhubungan dengan adat istiadat dan kepercayaan. Mantra digunakan atau diucapkan pada waktu dan tempat tertentu yang memiliki tujuan untuk menimbulkan kemampuan tertentu bagi orang yang mengucapkannnya. Mantra biasanya dikuasai oleh orang-orang tertentu, seperti dukun atau pawang.

Menurut KBBI (Penyusun, 2013), mantra adalah perkataan atau ucapan yang memiliki kekuatan gaib (misalnya dapat menyembuhkan, mendatangkan celaka, dsb) atau dapat juga diartikan susunan kata berunsur puisi (spt rima, irama) yang dianggap mengandung kekuatan gaib, biasanya diucapkan oleh dukun atau pawang untuk menandingi kekuatan gaib yang lain (hlm. 876).

Mantra biasanya dimiliki oleh masyarakat Dayak, seperti mantra tatamba (mantra untuk penyembuhan), mantra kapidaraan (mantra diganggu makhluk halus, mantra upacara adat, dan lain-lain. Sementara itu, mantra yang direfleksikan dalam novel Jendela Seribu Sungai, antara lain, mantra upacara adat dan mantrapenyembuhan (tatamba). Perhatikan mantra-mantra berikut ini.

"Sambut alih dewata umbaian ada umbaian padi. Sambutnalih Nini Bahatara raja kawasa, karana sida yang mancipta bumi langit. Sambut alih Tuhan yang Maha Esa yang kuasa segala-galanya. Kami maminta janjirani, minta payungani, minta paliharai susungkuhan, saharunang, sabalaian, sabanuaan. Minta baik, minta manang, minta salamatan, minta baapuah, minta barajaki."

"bubuhan ruh gaib, ruh jahat, ruh jin, ruh setan tulakan alih sida jauhakan kaluar langit, kaluar gunung sebab sida anu jaya, anu sakti, anu kuwasa. Pati kami manusia mamasang sabuk dahupa, sabuk dumarin kukusnya jadi tumpakan, jadi titian, jadi jambatan nang bahandung ka balai langit, balai manang, ke balai ratu dewata."....( Miranda \& Avesina, 2018, hlm. 2-3)

Mantra di atas adalah mantra yang dibaca oleh balian-balian pada saat prosesi mandiwata bapanaik. Sebagai sebuah budaya, mandiwata bapanaik adalah prosesi upacara yang dilakukan oleh masyarakat Dayak. Mantra tersebut dibaca dengan tujuan menurunkan para dewa yang dilaksanakan sebelum palas: 
penyucian. Pada saat pembacaan mantra hanya terdengar bunyi gemerincing gelang kuningan.

Selain mantra di atas berikut mantra yang dibaca dalam prosesi penyembuhan.

"babantang sabuk dahupa, sabuk dumarin. Urang cakap jadi titian, jadi tumpakan.kau membuka lawing sahabat, urang banyak basahabat, banyak bawaraka, banyak bakapihan. Turun sahabat nu ampat badangsanak, nang ampat badanghiyang." (Miranda \& Avesina, 2018, hlm. 224).

Mantra tersebut dibaca Damang Isman dalam prosesi penyembuhan atau masyarakat Dayak menyebutnya tatamba. Mantra yang dibaca adalah mantra penghubung manusia dengan para dewata yang mereka percaya. Dalam upacara tatamba itu biasanya disertai persembahan (sesaji) yang berupa lemang, bunga, sirih, rokok, dan mayang pinang. Sesaji tersebut ditempatkan pada aruh ganal. Denting gelang hyang dengan tabuhan gendang terdengar ritmis dan magis. Mantra tersebut dibaca semakin cepat oleh Damang Isman dengan iringan tabuhan yang semakin rapat dan meninggi.

Berikut juga mantra penyembuhan yang dibaca oleh Kejora saat Arian tertabrak motor.

"Buka lawing kulit, lawing darah, lawing daging, dalam kulit, dalam jantung, ambilakan ulih awak habishabis, tundungakan, rajahakan."

"Hancurakan penyaitnya dalam darah. Jadiakan air, jadiakan angin, titik air mula ada, mula jadi." (Miranda \& Avesina, 2018, hlm. 155).

Mantra tersebut semacam mantra tatamba, ritus penyembuhan orang Dayak Meratus. Ketika Kejora membaca mantra tersebut, Arian merasakan rasa hangat menjalar di sekujur tangannya. Ketika mantra dibacakan hanya orang yang diobati yang bisa merasakan kekuatan mantra tersebut.

Bagi masyarakat Banjar, mereka lebih mengenal doa. Walaupun tidak menutup kemungkinan mereka juga percaya pada hal-hal yang gaib. Hal itu dikarenakan masyarakat Banjar mayoritas beragama Islam. Pengaruh ajaran Islam sangat melekat pada seluruh aspek kehidupan orang Banjar. Hal itu dapat dilihat dari kutipan berikut.

"Lelaki itu kemudian duduk di sebuah bangku panjang sambil memilin-milin tangan. Berkali-kali matanya melirik pintu kaca yang tertutup rapat. Ia tidak ikut ke dalam bukan karena takut, melainkan aturan rumah sakit yang tidak membolehkan.

"Hannaa Waladat Maryama Wa Maryama Waladat "lisaa Ukhruj Ayyuhal Mauluudu Biqudrotil Malikil Ma"buudi..." (Miranda \& Avesina, 2018, hlm. 22)

Amalan yang berupa doa dibaca seorang suami yang sedang menunggu istrinya melahirkan. Mereka percaya dengan membaca doa tersebut seorang istri yang akan melahirkan akan diberi keselamatan, termasuk anak yang akan dilahirkannya.

Kutipan di atas merupakan bagian dari cerita novel Jendela Seribu Sungai yang menggambarkan seorang suami yang sedang menunggu istrinya melahirkan. Sambil menunggu suami tersebut mengamalkan doa tersebut. Benar saja tidak berapa lama seorang perempuan dengan melepas jubah hijau dan masker mengahmpiri lelaki tersebut dan mengucapkan selamat bahwa anaknya telah lahir dengan selamat. 
Meski Islam menjadi identitas orang Banjar, dalam penampakannya corak keislaman orang Banjar mencakup pada konsepsi-konsepsi yang berasal dari imigran dan tradisi Melayu, dari sisa-sisa kepercayaan Hindu, dan sisa kepercayaan Dayak yang ikut membentuk suku dan kebudayaan Banjar (Wajidi, 2011, hlm. 61).

\section{PENUTUP}

\section{Simpulan}

Kajian etnolinguistik dalam penelitian ini terkait hubungan bahasa dengan budaya. Berdasarkan kajian tersebut ditemukan budaya masyarakat Banjar dan Dayak yang direfleksikan melalui tokoh dalam novel Jendela Seribu Sungai karya Miranda Seftiana dan Avesina Soebli. Refleksi budaya Banjar dan Dayak dalam novel Jendela Seribu Sungai, yaitu: (1) tradisi dan adat kebiasaan masyarakat Banjar ada upacara adat mandi tian mandaring; (2) refleksi ungkapan dan peribahasa terdapat ungkapan bauntung batuah, sandu bakut, dan peribahasa kada titik banyu diganggam; (3) refleksi ritual dan kepercayaan terdapat kapidaraan, bapalas, tatamba, dan kamurawaan; (4) refleksi permainan tradisional terdapat permainan batarik upih dan bapidak; (5) refleksi makanan tradisional terdapat cacapan, garih batanak, dan pundut; (6) refleksi mantra terdapat mantra untuk upacara adat dan mantra untuk penyembuhan (tatamba).

\section{DAFTAR PUSTAKA}

Banua, H. (2020). Nostalgia mainan bapidak bigi Para. Retrieved from www.visitkalsel.com website: https://www.visitkalsel.com/nosta lgia-mainan-bapidak-bigi-para/
Danandjaja, J. (2002). Folklor ilmu gosip, dongeng, dll. jakarta: Pusaka Utama Grafiti.

Duranti, A. (1997). Lingusitic anthropology. California: Cambridge University Press.

Endraswara, S. (2015). Etnologi Jawa: Penelitian, perbandingan, dan pemaknaan budaya. Yogyakarta: Center for Academic Publishing Service.

Faruk. (2012). Pengantar sosiologi sastra. Yogyakarta: Pustaka Pelajar.

Foley, W. (2001). Anthropological linguistics. Massachusetts: Blackwell Publisher Inc.

Hanafi, N. (2020). Refleksi budaya lampau leksikon kebendaan peribahasa Banjar: Kajian etnolinguistik. Undas: Jurnal Hasil Penelitian Bahasa dan Sastra, 16(1), 93-106.

https://doi.org/https://doi.org/10 .26499/und.v16i1.2176

Hasanah, Z. (2013). Suku Banjar di Kalimantan. Retrieved from 23 April 2013 website: http:/ / zeinhasanah1207.blogspot.co m/2013/04/suku-banjar-dikalimantan_25.html

Hermoyo, Hidayah, N., Yarno, \& Panji, R. (2016). Representasi budaya Jawa dan Barat dalam novel Rahvayana karya Sujiwo Tejo. Stilistika, 9(2), 6279. Retrieved from journal.umsurabaya.ac.id/index.php/Stilistika /article/

Kurniati, E. (2016). Permainan tradisional dan perannya keterampilan kosial anak. Jakarta: Prenamedia Group.

Marzoan, \& Hamidi. (2017). Permainan 
tradisional sebagai kegiatan ekstrakurikuler untuk meningkatkan Kompetensi sosial siswa. Journal An-Nafs: Kajian Penelitian Psikologi, 2(1), 62-82. https://doi.org/https://doi.org/10 .33367/psi.v2i1.345

Miranda, S., \& Avesina, S. (2018). Jendela seribu sungai. Jakarta: PT. Grasindo.

Mulyani, N. (2016). Permainan tradisional anak Indonesia. Yogyakarta: DIVA press.

Penyusun, T. (2013). Kamus besar bahasa Indonesia (IV; H. Alwi, Ed.). Jakarta: Balai Pustaka.

Ratna, N. K. (2013). Teori, metode, dan teknik penelitian sastra. Yogyakarta: Pustaka Pelajar.

Sarbaini. (2016). Baiman, banuntung dan Batuah sebagai sosok harapan urang banua: Kajian awal etnopedagogi. Retrieved from https://sarbainifkipunlam.blogspot .com website: https:// sarbainifkipunlam.blogspot .com/2016/02/baiman-bauntungdan-batuah-sebagai.html

Sari, Y. P. (2019). Nilai budaya dalam leksikon pendulangan intan pada masyarakat Banjar: Kajian etnolinguistik. Undas: Jurnal Hasil Penelitian Bahasa Dan Sastra, 15(2), 161-174. https://doi.org/10.26499/und.v15i 2.1701

Sibarani, R. (2004). Antropolinguistik: Antropologi linguistik, linguistik antropologi. Medan: Penerbit Poda.

Sugianto, A. (2015). Kajian etnolinguistik terhadap peribahasa etnik Jawa Panaragan sebuah tinjauan pragmatik force. In Sigit Haryanto,
Burhanuddin, \& H. Pratama (Eds.), Seminar Nasional PRASASTI II "Kajian Pragmatik Dalam Berbagai Bidang (pp. 51-55). https://doi.org/https://doi.org/10 .20961/pras.v0i0.57

Sugiyono. (2012). Metode penelitian pendidikan: Pendekatan kuatitaif, Kualitatif, dan RED. Bandung: Alfabeta.

Sztompka, P. (2008). Sosiologi perubahan sosial. Dialihbahasakan oleh Alimandan. Jakarta: Prenada.

Tumanggor, R., Ridlo, K., \& Nurochim. (2010). Ilmu sosial \& budaya dasar. Jakarta: Kencana Prenada Media Group.

Upacara adat Kalimantan Selatan. (2013). Retrieved September 25, 2020, from www.UpacaraTradisi.blogspot.com website: https://upacaratradisi.blogspot.co $\mathrm{m} / 2013 / 04$ /upacara-adatdikalimantan-selatan.html

Wajidi. (2011). Akulturasi budaya Banjar di Banua Halat. Yogyakarta: Pustaka Book Publisher.

Wikipedia. (2020). Retrieved September 14, 2020, from https://ms.wikipedia.org website: https://ms.wikipedia.org/wiki/Tai k_upih

Yulianti, A. I. (2018). Leksikon dalam upacara kematian (tiwah) suku Dayank Ngaju. Suar Betang, 13(1), 65-74. https://doi.org/https://doi.org/10 $.26499 /$ surbet.v13i1.68 